\title{
PECULIARIDADES HISTÓRICAS, PANORAMA ATUAL E DESAFIOS NA FORMAÇÃO DE PROFESSORES DOUTORES
}

\author{
PECULIARIDADES HISTÓRICAS, PANORAMA ACTUAL Y DESAFÍOS EN LA \\ FORMACIÓN DOCTORAL DOCENTE
}

\author{
HISTORICAL PECULIARITIES, CURRENT PANORAMA AND CHALLENGES IN \\ DOCTORAL TEACHER EDUCATION
}

\author{
Ana Silvia Alves GOMES ${ }^{1}$ \\ Ana Cristina Pimentel Carneiro de ALMEIDA ${ }^{2}$
}

\begin{abstract}
RESUMO: Este trabalho analisa alguns aspectos que vêm sendo discutidos a respeito dos doutorados no Brasil e no Mundo. Examina sobre que aspectos tais discussões repercutem na própria formação doutoral e/ou podem ajudar a encarar os desafios e as responsabilidades inerentes à função de professor-pesquisador que tal título acadêmico ratifica. Basicamente, está dividido em quatro partes interdependentes. Primeiramente apresenta um breve histórico da origem e evolução dos cursos de doutorado em universidades medievais europeias, para situar o leitor das peculiaridades históricas relacionadas às atribuições e formação de doutores. Em seguida discute a situação e configuração atual dos cursos de doutorado e alguns problemas identificados por pesquisas realizadas em programas de pós-graduação de diferentes universidades. Posteriormente relata algumas reflexões particulares sobre a experiência de uma das autoras como aluna de pós-graduação e, finalmente, discute alguns desafios específicos de atuais e futuros doutores da área educacional.
\end{abstract}

PALAVRAS-CHAVE: Doutorado. Formação de professores. Educação superior.

RESUMEN: Este artículo analiza algunos aspectos que se han discutido sobre los doctorados en Brasil y en todo el mundo. Examina la medida en que tales discusiones impactan la capacitación doctoral en sí y/o pueden ayudar a abordar los desafíos y las responsabilidades inherentes al papel de profesor-investigador que dicho título académico ratifica. Básicamente, se divide en cuatro partes interdependientes. En primer lugar, presenta una breve historia del origen y la evolución de los cursos de doctorado en las universidades medievales europeas, con el fin de ubicar al lector de las peculiaridades históricas relacionadas con las atribuciones y la formación de los doctores. Luego discute el estado actual y la configuración de los programas de doctorado y algunos problemas identificados por la investigación realizada en programas de posgrado en diferentes universidades. Después informa sobre algunas reflexiones particulares sobre la experiencia de uno de los

\footnotetext{
${ }^{1}$ Universidade Federal do Pará (UFPA), Belém, PA - Brasil. Doutoranda no Programa de Pós-Graduação em Educação em Ciências e Matemática do Instituto de Educação Matemática e Científica da UFPA. ORCID: 00000003-0310-0413.E-mail: anasilviaalves@gmail.com

${ }^{2}$ Universidade Federal do Pará (UFPA), Belém, PA - Brasil. Docente do Programa de Pós-Graduação em Educação em Ciências e Matemática do Instituto de Educação Matemática e Científica da UFPA. Doutora em Desenvolvimento Sustentável do Trópico Úmido pela Universidade Federal do Pará (2005). ORCID: 00000002-9432-2646. E-mail: anacpca@ufpa.br
}

RIAEE - Revista Ibero-Americana de Estudos em Educação, Araraquara, v. 15, n. 2, p. 578-596, abr./jun. 2020. e-ISSN: 1982-5587. 
autores como estudiante de posgrado, y finalmente analiza algunos desafíos específicos para los actuales y futuros doctores del campo de la educación.

PALABRAS CLAVE: Doctorado. Formación docente. Educación superior.

ABSTRACT: This article analyzes some aspects that have been discussed about doctorates in Brazil and around the world. It examines the extent to which such discussions impact doctoral training itself and / or can help address the challenges and responsibilities inherent in the role of professor-researcher that this academic degree ratifies. Basically, it is divided into four interdependent parts. First, it presents a brief history of the origin and evolution of doctoral courses in European medieval universities, in order to locate the reader of the historical peculiarities related to the attributions and training of doctors. He then discusses the current status and configuration of the doctoral programs and some problems identified by the research carried out in postgraduate programs in different universities. Then he reports on some particular reflections on the experience of one of the authors as a graduate student, and finally analyzes some specific challenges for current and future doctors in the field of education.

KEYWORDS: Doctorate. Teacher education. Higher education.

\section{Introdução}

Uma busca simples em um bom indexador de artigos científicos mostra que há uma significativa quantidade de artigos de pesquisa em língua inglesa sobre diferentes fatores sociais, culturais e institucionais relacionados à experiência em cursos de doutorado. O estudo de Jones (2013), por exemplo, faz uma revisão de 995 artigos sobre esse tema para tentar avaliar a probabilidade dessas experiências terem efetivamente produzido um resultado de doutorado oportuno e bem-sucedido.

A ideia deste texto é tentar sintetizar alguns aspectos que vêm sendo discutidos a respeito dos doutorados no Brasil e no Mundo e, a partir daí, refletir sobre que pontos tais discussões refletem formação doutoral das autoras e/ou podem ajudar a atuais e futuros doutores a encarar os desafios e as responsabilidades inerentes à função de professorpesquisador que tal título acadêmico ratifica.

O texto está dividido em quatro partes interdependentes. Primeiramente apresenta-se um breve histórico da origem e evolução dos cursos de doutorado em universidades medievais europeias, para situar o leitor das peculiaridades históricas relacionadas às atribuições e formação de doutores. Em seguida discute-se a situação e configuração atual dos cursos de doutorado e alguns problemas identificados por pesquisas realizadas em programas de pós-graduação de diferentes universidades no Brasil. Posteriormente são debatidos alguns 
desafios inerentes ao processo de formação de pesquisadores. E, finalmente, relatam-se algumas reflexões particulares sobre a experiência de uma das autoras como aluna de pósgraduação e alguns desafios específicos de atuais e futuros doutores da área educacional.

\section{Breve histórico do doutorado}

De acordo com Le Goff (2003), o primeiro doutorado concedido por uma Universidade medieval foi concedido pela Universidade de Paris, por volta de 1150 d.C. Todavia, pelo menos duzentos anos antes, o título de Doutor - cuja palavra deriva do Latim doceo - já existia como uma espécie de licença para ensinar Latim em certas universidades medievais (Licentia docendi). Segundo Manacorda (2006), na igreja primitiva o termo doutor fazia referência aos apóstolos, pais da igreja cristã e outras autoridades eclesiásticas que ensinavam e interpretavam a Bíblia. Com o tempo, as autoridades da igreja católica romana passaram a conceder a chamada licentia docendi (ou seja, o doutorado), exigindo que o candidato passasse por um teste, prestasse um juramento de lealdade e pagasse uma taxa. Em 1213 d.C. o Papa Inocêncio III concedeu oficialmente o direito à Universidade de Paris titular seus próprios doutores, que se tornou uma licença universal para ensinar (licentia ubiquie docendi). No entanto, a chamada Licentia continuava a manter um prestígio mais elevado do que o grau Baccalaureus, e logo passou a ser considerado um passo intermediário para doutoramento, o Magister (MANACORDA, 2006).

No Século XVII o doutorado em filosofia (Phil Dr) desenvolveu-se nas cidades da região onde hoje está localizada a Alemanha (CLARK, 1992). O termo "filosofia" não se refere apenas ao campo ou disciplina acadêmica da filosofia, mas é usado em um sentido mais amplo de acordo com o seu significado original grego, que é "amor à sabedoria". Na maior parte da Europa, todos os campos (história, filosofia, ciências sociais, matemática e filosofia natural/ciências naturais) eram tradicionalmente conhecidos como filosofia e, nos reinados da atual Alemanha e em outros lugares da Europa, a faculdade básica das artes liberais era conhecida como "faculdade de filosofia". O doutorado de filosofia adere a esta convenção histórica, embora os graus nem sempre sejam para o estudo da filosofia estritamente falando (CLARK, 1992).

Com as reformas universitárias de Von Humbolt do inicio do Século XIX, o doutorado de filosofia passou a ser considerado um grau para pesquisadores do mais alto gabarito (CLARK, 1992; CASPER; HUMBOLDT, 1997). 
O doutorado universitário foi uma forma de aprendizado para uma guilda ${ }^{3}$. O tempo tradicional de estudo antes dos novos professores serem admitidos na guilda de "Mestres de Artes! era de sete anos. Originalmente, os termos "mestre" e "doutor" eram sinônimos, mas com o passar do tempo o doutorado passou a ser considerado uma qualificação superior à do mestrado (COSTA, 2014).

O uso e o significado do termo doutorado mudaram ao longo do tempo e ainda estão sujeitos a variações regionais. Por exemplo, até o início do século XX, poucos acadêmicos ou professores de universidades de língua inglesa possuíam doutorados, com exceção de eruditos muito graduados e aqueles em ordens sagradas (CLARK, 1992).

A mudança das universidades alemãs para uma educação orientada para a pesquisa (baseada no método científico, pesquisa e observação) aumentou a importância do doutorado. Hoje, um doutorado em pesquisa ou seu equivalente é geralmente um pré-requisito para o início de uma carreira docente universitária, embora muitos doutores não trabalhem na academia.

Segundo Clark (1992), no Reino Unido, os doutorados em pesquisa inicialmente tomaram a forma de doutorados superiores, introduzidos pela primeira vez na Universidade de Durham em 1882, se espalharam para o Reino Unido dos EUA via Canadá e foram instituídos em todas as universidades britânicas a partir de 1917 (intitulado um DPhil).

Os doutorados de estilo antigo, agora geralmente chamados de doutorados superiores no Reino Unido, levam muito mais tempo para serem concluídos, uma vez que os candidatos devem se mostrar especialistas em seus assuntos. Estes doutorados são agora menos comuns em alguns países e são frequentemente premiados com o título de honoris causa. A habilitação ainda é usada para fins de recrutamento acadêmico em muitos países da União Europeia e envolve uma nova tese longa (um segundo livro) ou um portfólio de publicações de pesquisa. A habilitação (maior grau disponível) demonstra pesquisa independente e completa, experiência em ensino e palestras e, mais recentemente, a capacidade de obter financiamento de pesquisas. Atualmente, na Alemanha e em grande parte dos países europeus, a habilitação de doutorado de pesquisa é um requisito mínimo para a nomeação como professor de universidades.

\footnotetext{
3 Associação que agrupava, em certos países da Europa durante a Idade Média, indivíduos com interesses comuns (negociantes, artesãos, artistas) e visava proporcionar assistência e proteção aos seus membros.
} 


\section{A situação atual dos doutorados no Brasil}

No Brasil, normalmente, os candidatos a doutorandos devem ter concluído anteriormente um mestrado em um campo relacionado. Exceções são baseadas em eventual mérito acadêmico individual acima da média. Uma segunda e uma terceira língua estrangeira são outros requisitos comuns, embora os requisitos relativos à proficiência comumente não sejam rígidos. O processo de admissão varia por instituição. Alguns exigem que os candidatos façam testes, enquanto outros baseiam as admissões na apresentação de uma proposta de pesquisa e entrevista apenas. Em ambos os casos, no entanto, um membro do corpo docente deve concordar, antes da admissão, em orientar o candidato.

Os requisitos para obtenção do título de Doutor geralmente incluem desempenho satisfatório em cursos de pós-graduação avançados, aprovação em um exame de qualificação oral e apresentação de uma tese que deve representar uma contribuição original e relevante para o conhecimento existente em uma área específica de pesquisa.

O grau de Doutor geralmente permite que um indivíduo se candidate a um cargo de professor adjunto em universidades brasileiras. No sistema universitário federal, por exemplo, os doutores que são admitidos como docentes adjuntos podem progredir (normalmente por tempo de atuação e produtividade acadêmica) para o posto de professor associado e, em seguida, tornarem-se elegíveis para fazer o exame para cargos de professores titulares. $\mathrm{Na}$ maioria das universidades do Brasil, para que os professores associados ascendam à professores titulares, além do título de doutor, são exigidos uma segunda tese ou um portfólio cumulativo de publicações revisadas por pares, uma palestra pública perante um painel de especialistas (incluindo membros externos de outras universidades) e, às vezes, um exame escrito.

Atualmente, profissionais em muitos campos, estabelecidos e emergentes, estão realizando pesquisas de doutorado em números sem precedentes no Brasil. Uma consequência do aumento da oferta de cursos de pós-graduação, produto de orientações específicas de políticas públicas com foco na formação de doutores como ferramenta para construir uma economia baseada no conhecimento e inovação (GODINHO, 2007).

Nos últimos 20 anos, houve um rápido crescimento e mudança na formação em pesquisa de doutorado no mundo todo (MARCHELLI, 2005). Em um sentido importante, o próprio doutorado é um campo emergente, em estado de constante transformação. No Brasil, além das áreas mais tradicionais, foram instituídos diversos programas em áreas 
multidisciplinares e para atender uma demanda reprimida que se encontrava principalmente fora do chamado eixo Rio-São Paulo (CAPES, 2017).

Figura 1 - Variação da quantidade de programas de pós-graduação em universidades brasileiras (CAPES, 2017)

\section{Crescimento dos cursos de pós-graduação}

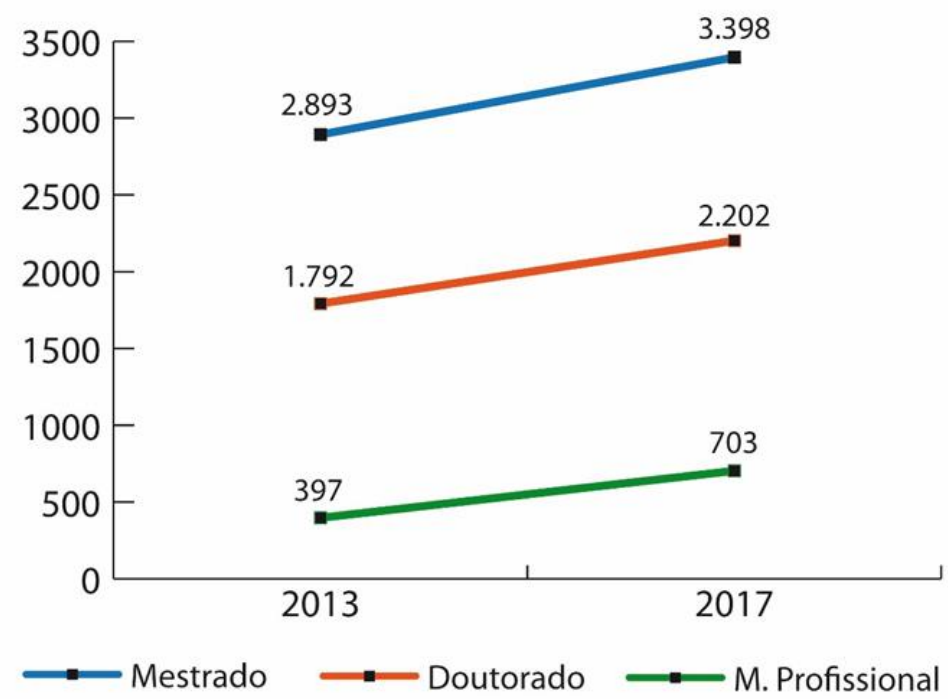

Fonte: elaborado pelos autores.

Recentemente, a CAPES estimulou a criação dos chamados doutorados profissionais com o intuito de construir uma forma distinta de pesquisa baseada na prática profissional e tecnologia aplicada (BRASIL, 2017). Os propósitos e formas desses novos tipos de doutorado foram reorientados de uma preocupação com a produção de conhecimento disciplinar e a reprodução das disciplinas para preocupações com o desenvolvimento da força de trabalho, a mudança da prática profissional e a aprendizagem ao longo da vida. A formação doutoral foi, explicita ou implicitamente, deslocada para espaços de aprendizagem na interface entre os conhecimentos acadêmicos, profissionais e do local de trabalho.

\section{Alguns problemas enfrentados por doutorandos e recém-doutores}

Embora a princípio pareça salutar aumentar a quantidade de doutores em um país, isso necessariamente não se configura em uma boa política acadêmica se não estiver em harmonia com o mercado de trabalho, com uma política macroeconômica de desenvolvimento nacional e tenha um controle de qualidade rigoroso em constante avaliação e aperfeiçoamento. No Brasil, por exemplo, até 2015, a quantidade de doutores estava sendo bem absorvida pelo 
mercado de trabalho, embora já houvesse projeções de início de colapso de vagas para doutores (GALVÃO et. al, 2016). Quando a crise econômica e política em curso começaram a frear a expansão do sistema público de educação superior, principal destino dos doutores egressos de diferentes cursos de pós-graduação no Brasil, um significativo excedente de doutores ficou fora do mercado de trabalho ou atuando em empregos ou subempregos não relacionados à sua formação acadêmica (SAYURI, 2018).

Outro problema sério está relacionado às exigências socioemocionais que um aluno de doutorado está submetido. Um estudo realizado por Louzada e Silva Filho (2005) com 21 pós-graduandos de universidades paulistas revelou que o sofrimento fazia parte do processo de formação dos pesquisadores entrevistados; manifestava-se em diversos níveis de intensidade e aparecia nomeado de múltiplas formas. Tal sofrimento, apesar de ter sido detalhadamente explorado por poucos, foi referido por todos os entrevistados, ainda que tangencialmente. Eventualmente esse sofrimento apareceu naturalizado; mas foi possível vêlo também remetido a determinadas regras existentes no campo científico.

Para Louzada e Silva Filho (2005), esses sintomas estão diretamente relacionados às relações e condições de trabalho; às regras de fomento; à equipe de pesquisa; às colaborações estabelecidas; à posição do laboratório no campo; ao nível de reconhecimento científico do orientador; à posição do programa de pós-graduação; ao estilo do orientador, entre outros. Arranjos absolutamente singulares. Assim como não há um único modo de organizar um laboratório ou departamento, estabelecer colaborações ou parcerias em ciência, também não há uma única maneira dos estudantes responderem às exigências da formação científica. Não há, enfim, um único modo de fazer pesquisa nem de formar pesquisadores. As combinações possíveis, entre todas as variáveis citadas, impactam o processo de formação como um todo e exigem reflexão permanente tanto dos discentes quanto dos seus orientadores.

Outro problema relativamente preocupante com os cursos de formação de doutores refere-se à aparente falta de preparação para a docência dos seus egressos. Uma pesquisa desenvolvida por Arroio, Rodrigues Filho e Silva (2006), junto a uma amostra de concluintes de cursos de pós-graduação em Química da USP, por exemplo, detectou que $75 \%$ dos entrevistados não se sentiam preparados para exercer a função docente no ensino superior, principalmente por "insegurança", "falta de preparação", ao passo que os que se sentiam preparados apenas declaravam "estar preparados", sem conseguir detalhar um motivo sequer para tal avaliação. É bem possível que essa "herança" seja assistematicamente repassada, geração em geração de futuros doutores. 
Tanto o problema do sofrimento durante o processo de formação doutoral quanto as deficiências na preparação para a docência estão diretamente relacionados ao papel e influência dos orientadores de doutorado, que é outra questão crucial para a formação de bons pesquisadores e merece uma discussão um pouco mais longa do que os três problemas anteriormente mencionados.

A análise de entrevistas de 26 orientadores de doutorado da área de ciências humanas de universidades australianas, realizada por Halse (2011), investigou quais as principais peculiaridades da relação entre orientador e orientando e como isso ocorre ao longo do tempo de acúmulo de experiência como orientador de doutorado. Durante as entrevistas, os orientadores foram instruídos a descrever detalhadamente suas experiências, eventuais mudanças nas condições culturais da universidade nas últimas décadas e o impacto dessas mudanças no seu trabalho, nas experiências com seus alunos de doutorado e nas suas próprias práticas como orientadores.

A maioria dos entrevistados relatou que ao longo dos últimos anos ocorreram mudanças significativas que alteraram toda a dinâmica de formação pela qual eles mesmos passaram na ocasião em que fizeram seus respectivos cursos de doutorado:

Fazer um doutorado significava ter tempo para ler, pensar e discutir teorias, ideias e o trabalho de outros estudiosos. Isso não era uma indulgência, mas uma parte importante do trabalho de fazer um doutorado e se tornar um estudioso. Agora esse processo está truncado. Temos que garantir que nossos alunos concluam em três anos antes que o financiamento acabe. Por isso, direcionamos o trabalho deles, fornecemos listas de leitura em vez de enviálos para a biblioteca para mergulhar na literatura e fornecer resumos do trabalho dos principais pensadores (Orientador de Doutorado em Educação) (HALSE, 2011, p. 560).

As análises propostas por Halse (2011) sugerem que com o passar do tempo e as mudanças curriculares, expansão da quantidade de discentes e critérios de avaliação dos programas, os orientadores intuitivamente tiveram que alterar suas práticas de orientação ao longo dos anos. Em um contexto de maior produtividade e responsabilidade com os prazos, os orientadores aprenderam a usar estratégias de autoproteção contra a perda de status e certas penalidades que poderiam sofrer se houvesse um evento negativo no qual pudessem ser considerados culpados, como um relatório de um aluno criticando a atuação do orientador, falha em cumprir prazos determinados ou feedback crítico de um examinador da banca.

Segundo Halse (2011), as medidas típicas de autoproteção mencionadas pelos orientadores incluem: ser muito diretivo na formação e orientação do trabalho dos alunos; desencorajar os estudantes de métodos e análises de risco intelectuais ou métodos de pesquisa 
demorados; ultrapassar os limites entre revisar e escrever as teses dos alunos, fornecendo feedback excessivamente detalhado sobre o trabalho dos alunos; usar dinheiro de subvenção de universidades e pesquisas para empregar analistas de dados, assistentes de pesquisa, redatores de redações, revisores e editores para acelerar o progresso dos alunos ou atenuar as lacunas nas habilidades dos alunos; modificações dos critérios de validação científicas das pesquisas, em geral, flexibilizando aqueles que dificultavam a apresentação de pesquisas de natureza mais qualitativa e interpretativa. Além disso, Halse (2011) constatou que, rotineiramente, os orientadores, antecipando a possibilidade de um atraso na conclusão, já tinham em mãos justificativas padronizadas para os eventuais atrasos na defesa de tese, uma vez que isso vinha se tornando cada vez mais frequente.

Para alguns orientadores entrevistados por Halse (2011), aprender a orientação disciplinada envolvia ignorar conscientemente o modo de orientação que apreciavam durante seu próprio doutorado - um período de independência, estudo estendido e liberdade irrestrita para explorar sua área de pesquisa, com orientação mínima ou interferência do seu orientador.

Eu penso no meu próprio modelo quando eu era estudante de doutorado, meu orientador nunca insistiu. Ele sempre estava lá, se eu o quisesse, mas ele nunca pediu para me ver, ele leu tudo imediatamente e mandou de volta para mim e comentou, mas nunca exigia nada. Não houve relatórios anuais, não houve vigilância. Foi a antítese completa de todo esse tipo de sistema moderno, eu prosperei e terminei meu doutorado em dois anos e meio (Orientador de Doutorado em Psicologia) (HALSE, 2011, p. 564).

Embora usassem sistematicamente as estratégias de autoproteção e adaptação mencionadas, Halse (2011) sugere que, de várias maneiras e em graus variados, todos os orientadores entrevistados descreveram o esforço que fazem para aprender a ser mais adaptáveis e sensíveis às necessidades de seus alunos, procurando desenvolver uma compreensão de seus próprios temperamentos e capacidades pessoais e aprender a administrálos na relação pedagógica. Segundo Halse (2011), isso não era um trabalho fácil para os orientadores, pois envolvia aprender a estabelecer uma 'pessoa orientadora' que maximizasse os resultados de seus compromissos com os alunos, minimizando as disposições pessoais ou comportamentos que poderiam impactar negativamente no relacionamento aluno/orientador, como ser impaciente, inflexível, intolerante, arrogante ou excessivamente exigente.

A orientação de doutorado também exigia, segundo Halse (2011), que os orientadores aprendessem com seus erros e falhas. Não importa o quão meticulosos ou laboriosos eles fossem, os orientadores cometiam erros de julgamento, forneciam conselhos ou instruções erradas, ou avaliavam mal o impacto de suas instruções e feedback sobre os alunos. Os 
orientadores que aprenderam a confrontar seus erros e fracassos conseguiram desenvolver abordagens alternativas para o relacionamento pedagógico.

As análises das entrevistas realizadas por Halse (2011) nos ajudam a entender as complexas dinâmicas de poder que estão emaranhadas no relacionamento orientando/orientador. Em particular, que uma parte crítica do aprendizado do orientador envolve abandonar o investimento em seus próprios egos e poder. Ao que parece, foi através desses processos que os orientadores desenvolveram um canal de abertura para aprender sobre seus orientandos. Orientadores trabalhando com estudantes estrangeiros, por exemplo, descreveram conscientemente o esforço pessoal para dominar frases-chave na linguagem de seus alunos e aprender sobre as culturas e os costumes dos países dos estudantes para fazê-los sentir-se "em casa" e para assegurar que suas interações com os estudantes fossem culturalmente sensíveis, respeitosas e apropriadas (HALSE, 2011).

Nessa mesma linha, parte dos orientadores entrevistados por Halse (2011) também descreveu aprendizados ao tentar se "antenar" com as necessidades intelectuais e emocionais dos estudantes: oferecer liberdade quando os alunos estavam confiantes e seguros; fornecer orientação quando os estudantes estavam intelectualmente incertos; procurar compreender quando os alunos estavam fisicamente exaustos ou emocionalmente frágeis.

Apesar de ter sido realizado no contexto australiano, é provável que os resultados e análises demonstradas por Halse (2011) sejam pertinentes para o contexto brasileiro, tanto para orientadores quanto para doutorandos que, afinal de contas, serão os futuros orientadores de doutorado. Tomar consciência de problemas e saber como eles são tratados em determinados contextos pode ser útil para nosso aperfeiçoamento profissional tanto durante a formação doutoral quanto nos programas de formação de professores, nos quais eventualmente possamos atuar futuramente.

\section{Tornando-se um pesquisador}

Talvez seja lugar comum ver o fato de encarar o doutorado como um local particularmente intenso e significativo de "se tornar um pesquisador". Clegg e Gall (1998) observaram que a metáfora da "jornada" nas narrativas de doutorandos em se tornar um pesquisador é tão comum que merece alguma interrogação quanto ao seu poder explicativo. Segundo os autores, a ideia de "jornada" está ligada ao propósito, direção, duração e chegada a um lugar diferente, estão associadas a mudanças no tempo, espaço e circunstância; para narrativas de doutorado, elas são muitas vezes viagens de vida. Clegg e Gall (1998) relatam a 
onipresença da metáfora da jornada nas narrativas de doutorado e apontam para sua dinâmica transformadora. Segundo eles, para os profissionais que iniciam o estudo de doutoramento, há um ponto de partida, do conhecido e do dado, e um empreendimento de um movimento para um lugar desconhecido, um processo de aprendizagem e devir.

Segundo Green e Lee (1995), esses processos não são simplesmente uma questão de “conhecer", mas também de "vir a ser", isto é, de se tornar e ser uma certa autoridade em pesquisa. Embora as pesquisas citadas explicitem algumas peculiaridades sobre a formação doutoral, ainda há questões que permanecem em grande parte não examinadas na literatura de pesquisa sobre o doutorado, sobre o "tornar-se" um pesquisador profissional, em termos do que é negado e suprimido ou exposto e interrogado em relação à prática.

A aprendizagem de doutorado não pode ser encarada como uma aquisição não problemática de conhecimento, mas, como tantos outros processos de desenvolvimento humano, está carregado e incompleto de aprender a conhecer e a ser. Como dizem Green e Lee (1995), trata-se de um processo deleuziano de um "tornar-se-outro" de algum modo importante que envolve uma "tensão crucial", uma vez que o processo de formação doutoral exige:

[...] a injunção de ser "criativo" e "original" e de contribuir decisivamente e distintamente ao estoque atual de conhecimento, e ainda a impossibilidade de fazê-lo sem a devida autorização e autoridade enunciativa. Este último, paradoxalmente, só pode ser realizado após o evento, por assim dizer quando o grau é formalmente concedido e a tese aceita. Esta é uma tensão dialética do ser e do devir e da experiência vivida de duração e temporalidade (GREEN; LEE, 1995, p.43).

Para Green e Lee (1995) esse processo envolve tanto um "não-saber" quanto um "desaprender".

Em relação aos profissionais que estão iniciando um doutorado com foco profissional, há ainda mais tensões e ambiguidades entre as formas de conhecimento e os modos de ser da prática profissional e das culturas acadêmico-disciplinares. Lee, Brennan e Green (2009) denominaram esse conjunto de ideias implícitas como "currículo híbrido", que, segundo eles, procura posicionar o trabalho de doutorado em relação às economias simbólicas da universidade, profissão e local de trabalho, e é instável e ambíguo. Um conjunto de ideias que coloca em jogo não apenas o conhecimento do doutorando, mas também o objeto da pesquisa: a profissão, a organização e o local de trabalho que acaba sendo uma espécie de "motor" de um contínuo processo de tentativa e erro, através do qual toda a organização se move, se desenvolve e se desdobra. 
Para tentar explorar algumas reflexões sobre as dinâmicas e tensões do processo formativo em cursos de doutorado, uma das autoras deste trabalho decidiu expor um breve relato sobre seus próprios insights e experiências como uma pesquisadora iniciante. A fim de expressar opiniões sobre a experiência vivida nas atividades presenciais e nas leituras as quais tem se dedicado e procurado produzir notas de professora pesquisadora reflexiva (ZEICHNER, 1998), a qual pretende se tornar. Vejamos o que ela tem a nos dizer.

\section{Reflexões sobre as especificidades e desafios de uma doutoranda da área educacional}

Ao me perguntar sobre o que efetivamente tem contribuído para minha formação como pesquisadora não me resta nenhuma dúvida que se trata principalmente da ativa busca pela leitura de textos da área e escrita de anotações e ideias. As exigências acadêmicas do mestrado, e agora do doutorado, me obrigaram a manter uma contínua e sistemática rotina de leitura de textos relacionados à minha própria intenção de pesquisa, disciplinas e temas discutidos no grupo de pesquisa do qual participo.

Por conta da intenção e obrigação de escrever artigos percebi o quanto era importante ler artigos clássicos (não apenas os recém-publicados) para entender de forma mais consistente o que alguns autores mais recentes vêm falando em livros e artigos. Naturalmente essa busca pela compreensão em "fontes originais" me forçou a utilizar ferramentas da web de tradução de idiomas e praticar a leitura de textos em língua estrangeira, principalmente em inglês.

Durante esse percurso, após contato com as ideias de autores como Pérez-Gómes (1997), Zeichner (1998) e Contreras (2002), aumentei minha convicção de que escrever de maneira reflexiva sobre/em minha prática é fundamental para meu desenvolvimento profissional. Enquanto confesso que reflito dessa maneira menos do que acho que seria realmente necessário, por conta das minhas outras atribuições profissionais em curso, agora, cada vez mais, tenho cultivado essa prática como parte de minha vida profissional. Não sou de comprar muitos livros, mas mantenho uma pasta na minha conta do Google Drive intitulada 'reflexões de pesquisa', onde mantenho os artigos que li, devidamente marcados e comentados. A minha própria questão de pesquisa atual é fruto muito mais de minhas leituras sobre o contexto da formação de professores do que da vivência de minha prática profissional.

Embora ainda me sinta insegura sobre os possíveis resultados que poderei obter com a pesquisa que propus para compor minha tese de doutorado, sinto que estou no caminho certo. Sei disso ao perceber que outros colegas ainda estão tateando o que realmente pretendem 
pesquisar e, vez ou outra, testemunho a angústia deles em ainda não terem exatamente conseguido "casar" sua questão de pesquisa com um referencial teórico apropriado.

Obviamente, como já mencionei anteriormente, essas atitudes são frutos positivos das exigências do curso. Todavia, nem tudo são flores, os problemas práticos de conciliar tempo para as tarefas das disciplinas e grupos de pesquisa do curso com as atribuições profissionais de uma diretora de escola, entre elas, realizar a formação continuada dos professores, pois na Rede Municipal de Ensino no qual atuo, uma das atribuições do gestor é a realização da formação continuada no contexto de trabalho dos professores, não são deveras fáceis. Mas sigo em frente, grata a cada oportunidade, no devir formativo, que Lee (2011) diz ser a marca de formação de futuros pesquisadores. Tal como o referido autor comenta, não posso absolutamente garantir a chegada, apenas estou seguindo o caminho e encarando os desafios que me são apresentados.

Talvez fosse possível explorar ainda outros pontos de minhas lembranças e reflexões a respeito do meu percurso formativo no doutorado. Todavia por questões de limitação de espaço, creio que devo me concentrar a partir de agora em dois pontos cruciais a respeito do trabalho de conhecimento e identidade envolvido no "tornar-se doutor" - na verdade "tornarse um professor doutor", ou seja, a questão da evolução da escrita e consequente produtividade acadêmica e a questão da superação da dita racionalidade técnica.

$\mathrm{O}$ primeiro desses pontos diz respeito à produtividade da prática da escrita reflexiva em explorar o "devir" de um estudante de doutorado. Isso tem sido determinante pra mim. Durante as leituras, minhas reflexões escritas registram meus pensamentos, questionamentos e aprendizados, tornando-os disponíveis tanto para a recordação quanto para trabalhos futuros: aprofundam minha reflexão e também aumentam a oportunidade de integrar meu novo aprendizado a futuros textos de pesquisa.

Talvez a metáfora do "gotejamento" seja apropriada para expressar a relação entre o processo de leitura e escrita e seus efeitos em minha formação doutoral. Tal metáfora sugereme um processo lento, suave e orgânico que ocorre ao longo do tempo, no ambiente em que sua prática se desenrola. Pensei nisso para contrastar com as metáforas mecânicoinstrumentais de aquisição e aplicação de conhecimento que autores como Zeichner (1998) criticam em suas descrições de "trabalhador do conhecimento" mercantilizado.

Raelin (2007), outro autor que reflete sobre o processo de produção escrita em cursos de pós-graduação, fornece um relato útil das possibilidades da linguagem e da escrita em relação ao conhecimento sobre a prática. Raelin argumenta que conhecer a prática e a autocompreensão no contexto da pesquisa requer os recursos particulares da linguagem. A 
linguagem contribui para o entendimento não apenas como uma ferramenta para a autopercepção ou para comunicar o conhecimento adquirido, mas como um meio para criar conhecimento em primeira instância. Raelin (2007) cita a grounded teoria e a pesquisa-ação como ferramentas para desenvolver indutivamente nossas próprias teorias a partir dos dados da experiência ou das intervenções práticas. Essas práticas são "epistemologicamente étnicas", na medida em que privilegiam as percepções e visões de mundo dos membros da cultura sob investigação.

Watt (2007) também fala sobre o processo de escrita reflexiva, dizendo que há uma longa e bem estabelecida tradição dentro da pesquisa qualitativa que apoia esse tipo de processo como uma tecnologia que gera e registra conhecimento. Agora, vivenciando isso na prática, posso testemunhar sobre o valor da reflexão contínua e sistemática no processo de pesquisa de doutorado. Acredito que isso, lentamente, cada vez mais tem ajudado a me tornar uma aprendiz disposta e engajada nas práticas de um estudante de doutorado, quem sabe tornando-me uma pesquisadora-transformadora, capaz de reflexividade e autoconsciência, consciente dos processos e lutas necessárias em tais atividades práticas textuais.

Outro aspecto, mais específico da área de formação de professores, se relaciona ao desafio de superação da chamada racionalidade técnica. Ao tratar sobre isso, Pérez-Gomez (1997) critica, por exemplo, que as comissões de alto nível, geralmente doutores, que são encarregadas de redigir relatórios e elaborar diagnósticos, reformas e propostas para os "anacrônicos e insatisfatórios sistemas de formação de professores", geralmente possuem uma determinada concepção subjacente da escola e ensino, uma teoria do conhecimento e sua transmissão e aprendizagem, uma concepção própria das relações entre teoria e prática, entre investigação e a ação, que segundo o autor, podem ser expressos em dois modelos rivais, duas formas distintas de abordar os problemas que coloca a intervenção educativa e a atividade do docente como profissional do ensino: o professor como técnico especialista, que aplica com rigor as regras que derivam do conhecimento científico, e o professor como prático, autônomo, artista que reflete, toma decisões e cria durante sua própria ação.

A metáfora do professor como técnico tem suas origens no modelo da racionalidade técnica na qual a atividade profissional é, sobretudo, instrumental, voltada para solução de problemas mediante a aplicação rigorosa de teorias e técnicas científicas de investigação, assim como, seus princípios gerais. Daí seria derivada toda ação profissional eficaz. Nessa perspectiva, há o reconhecimento de uma hierarquia entre os níveis de conhecimento, bem como um processo lógico de derivação entre eles. Nesta concepção a formação do professor fica resumida a um conhecimento teórico e procedimental bem delimitado nos conteúdos e 
estrutura dos programas de formação por meio do componente científico cultural, que pretende assegurar o conhecimento do conteúdo que se pretende ensinar; e o componente psicopedagógico, que permite aprender como atuar eficazmente na sala de aula (PerezGomez, 1997).

Os limites e as lacunas da racionalidade técnica mostraram-se profundos e significativos principalmente porque a realidade social não se deixa encaixar em esquemas preestabelecidos do tipo taxonômico ou processual e as características dos fenômenos práticos como complexidade, incerteza, instabilidade, singularidade e conflito de valores são cada vez mais evidentes. Para Pérez-Gomez (1997), de um modo geral, na prática não existem problemas e sim situações problemáticas, que se apresentam frequentemente como casos únicos que não se enquadram nas categorias genéricas identificadas por técnicas ou teorias existentes.

Contudo, a racionalidade técnica teve o seu valor e representou avanços em diversos campos da ciência; além disso, críticos como Perez-Gomez (1997) não propõem o abandono generalizado da utilização da racionalidade técnica em qualquer situação da prática educativa. $\mathrm{O}$ que não se pode é considerar a atividade profissional do professor exclusiva e prioritariamente técnica.

Para Perez-Gomez (1997), dentre as consequências negativas da racionalidade técnica, além da hierarquização dos conhecimentos, também tivemos a diferenciação entre saber e fazer, dicotomização de posições e posturas arrogantes, dando demonstração de que existiriam profissionais para a academia e outros para a escola, como se esta fosse um espaço de trabalho inferior e não constituísse um espaço de produção de conhecimento na, sobre e para a prática docente: a racionalidade técnica formou docentes dependentes de uma fonte externa capaz de lhes suprir de conhecimento pronto.

Por outro lado, na concepção do professor como prático, segundo Perez-Gomez (1997), são destacados três conceitos interdependentes: conhecimento-na-ação, que se manifesta no saber fazer; reflexão-na-ação, a qual pode ser considerada o primeiro espaço de confrontação com a realidade problemática. No contato com a situação prática não só se adquirem e se constroem novas teorias, esquemas e conceitos, como se aprende o próprio processo dialético de aprendizagem; e reflexão sobre a ação e sobre a reflexão-na-ação: a análise que o indivíduo realiza a posteriori sobre as características e processos da sua própria ação. Quando o professor reflete na e sobre a ação converte-se num investigador em sala de aula. 
O pensamento prático do professor consiste em uma nova epistemologia da prática e conduz a reconsideração da função do professor como profissional, é de importância vital para compreender os processos de ensino-aprendizagem, para desencadear uma mudança radical dos programas de formação de professores e para promover a qualidade do ensino numa perspectiva inovadora (Perez-Gomez, 1997).

As atenções voltam-se para uma concepção reflexiva e artística da profissão docente e para modelos de formação que preparem os professores para o exercício desta arte nas situações divergente da prática. Nesse caso, o profissional competente atua refletindo na ação, criando uma nova realidade, experimentando, corrigindo e inventando através do diálogo que estabelece com essa mesma realidade (SCHÖN, 2000).

A racionalidade técnica prevalecente nos discursos da "economia do conhecimento" nega o complexo, rico e difícil processo de aprendizagem que constitui o devir-outro do profissional pesquisador. Concluindo, há desafios epistemológicos e ontológicos particulares que permanecem substancialmente inexplorados em relação à tarefa intelectual de pesquisar a prática como um objeto de preocupação em si e por si, em vez de, por exemplo, como meramente um local para a aplicação da teoria.

A tomada de consciência desses problemas e o posicionamento teórico e prático a respeito dessa disputa é desafio que atuais e futuros doutores do campo educacional, em particular, e professores da educação básica, em geral, devem estar atentos. A obtenção e manutenção do título de doutor trazem consigo benefícios e responsabilidades, essas últimas não podem ser simplesmente negligenciadas. Caso contrário, corre-se o risco de perpetuar ideias e práticas que não condizem com os ideais de um verdadeiro professor pesquisador.

\section{Considerações finais}

Com o intuito de refletir sobre o papel social e a situação atual dos egressos dos programas de doutorado, este manuscrito discutiu alguns aspectos históricos e o panorama contemporâneo da formação de doutores no Brasil, tentando explicitar alguns significados, problemas e desafios relacionados a esse tema.

Foi mostrado que, embora tenha se originado no seio do clero medieval e somente quatrocentos anos depois tenha sido estritamente vinculado a cientistas, o título de doutor sempre conferiu uma importância social bastante significativa aos seus portadores.

Embora no Brasil o número de programas de doutorado tenha aumentado de forma geral, e particularmente na área da Educação, ainda atinge somente uma pequena parcela da 
população, que, todavia, atualmente tem tido dificuldade de ser absorvida pelo mercado trabalho. O que demonstra a necessidade da implementação de uma política macroeconômica de desenvolvimento nacional focada no desenvolvimento científico e tecnológico, tal como as que foram implementadas com sucesso em outros países desenvolvidos, onde tais profissionais são mais facilmente absorvidos tanto pelo serviço público quanto por empresas da iniciativa privada.

Também foi discutido o quanto é pertinente considerar e pensar em medidas para mitigar as consequências do processo de sofrimento e pressão pelos quais muitos doutorandos são submetidos, assim como, o recorrente problema da pouca identidade com a docência de grande parte dos egressos dos cursos de doutorado.

Finalmente, ao refletir sob a condição de doutoranda da área educacional de uma das autoras do artigo, procura-se demonstrar o quanto o processo de formação de professores reflexivos - e consequente superação da ação docente meramente técnica - é um complexo, rico e difícil processo de aprendizagem que constitui o devir-outro do profissional pesquisador, de superação de desafios epistemológicos e ontológicos particulares que permanecem substancialmente inexplorados em relação à tarefa intelectual de pesquisar a prática como um objeto de preocupação em si e por si. O processo de produção escrita e escrita reflexiva, cujos resultados continuamente são analisados pelos pares, é o principal desafio que acaba compelindo os doutorandos a efetivamente assumirem o papel de pesquisadores-reflexivos, capazes de conduzir pesquisas pertinentes para suas respectivas áreas e para a sociedade e assim, de fato, fazer valer seus títulos de doutores.

\section{REFERÊNCIAS}

ANDRÉ, M.E.D.A. A complexa relação entre o professor e a pesquisa. In: ANDRÉ, M.E.D.A. (Org.) Papel da pesquisa na formação e na prática dos professores. São Paulo: Papirus, 2011. p. 27-54.

ARROIO, A; RODRIGUES FILHO, U.P; e SILVA, A.B.F. A formação do pós-graduando em Química para a docência em nível superior. Química Nova, v. 29, n. 6, p. 1387-1392, nov./dez. 2006. Disponível em:

http://www.scielo.br/scielo.php?script=sci_arttext\&pid=S0100-40422006000600040. Acesso em: jan. 2020. DOI: https://doi.org/10.1590/S0100-40422006000600040

BRASIL. Ministério da Educação. Portaria n. 389, de 23 de março de 2017. Dispõe sobre o mestrado e doutorado profissional no âmbito da pós-graduação stricto sensu. Diário Oficial da União, Brasília, 24 mar. 2017. Disponível em: http://www.in.gov.br/materia/- 
/asset_publisher/Kujrw0TZC2Mb/content/id/20482828/do1-2017-03-24-portaria-no-389-de23-de-marco-de-2017-20482789. Acesso em: jan. 2020.

CAPES. Avaliação da CAPES aponta crescimento da pós-graduação brasileira. Brasília: CCS/CAPES, 2017. Disponível em: http://www.capes.gov.br/sala-de-imprensa/noticias/8558avaliacao-da-capes-aponta-crescimento-da-pos-graduacao-brasileira. Acesso: jan. 2020.

CASPER, G; HUMBOLDT, W. Um mundo sem universidades? Rio de Janeiro: EdUERJ, 1997.

CLARK, W. On the ironic specimen of the doctor of philosophy. Science in context, v. 5, n. 1, p. $97-137,1992$.

CLEGG, S; GALL, I. The discourse of research degrees supervision: A case study of supervisor training. Higher Education Research \& Development, v. 1, n. 3, p. 323-332, 1998.

CONTRERAS, J. A autonomia de professores. Tradução de Sandra Trabucco Valenzuela. Edição Brasileira Selma Garrido Pimenta-São Paulo: Cortez, 2002.

COSTA, A.L.M.C. Títulos de Nobreza e Hierarquias: um guia sobre as graduações sociais na história. São Paulo: Draco, 2014.

GALVÃO, A.C.F. et al. O quadro recente de emprego dos mestres e doutores titulados no Brasil. Parc. Estrat, v. 21, n. 43, p. 147-172, 2016.

GODINHO, M. M. Indicadores de C\&T, inovação e conhecimento: onde estamos? Para onde vamos? Análise Social, n. 182, p. 239-274, 2007.

GREEN, B; LEE, A. Theorizing postgraduate pedagogy. The Australian Universities Review, v. 38, n. 2, p. 40-45, 1995.

HALSE, C. Becoming a supervisor: the impact of doctoral supervision on supervisors' learning. Studies in Higher Education, v. 36, n. 5, p. 557-570, 2011.

JONES, M. Issues in Doctoral Studies-Forty Years of Journal Discussion: Where have we been and where are we going? In: Proceedings of the Informing Science and Information Technology Education Conference. Informing Science Institute, 2013. p.83-104.

LE GOFF, J. Os intelectuais na Idade Média. Rio de Janeiro: José Olympio, 2003. LEE, A. Professional Practice and doctoral education: Becoming a researcher. In: SCANLON, L. (Ed), Becoming a professional: An interdisciplinary analysis of professional learning. London: Springer, 2011, p.153-169.

LEE, A.; BRENNAN, M.; GREEN, B. Re-imagining doctoral education: professional doctorates and beyond. Higher Education Research \& Development, v. 28, n. 3, p. 275287, 2009.

LOUZADA, R. C. R; SILVA FILHO, J. F. Formação do pesquisador e sofrimento mental: um estudo de caso. Psicologia em Estudo, Maringá, v. 10, n. 3, p. 451-461, 2005. 
MANACORDA, M. A. História da Educação: da Antiguidade aos nossos dias. 12. ed. São Paulo: Cortez, 2006.

MARCHELLI, P. S. Formação de doutores no Brasil e no mundo: algumas comparações. Revista Brasileira de Pós-Graduação, v. 2, n. 3, 2005.

PÉREZ-GÓMEZ, A. O pensamento prático do professor - a formação do professor como profissional reflexivo. In: NÒVOA, Antônio (Coord). Os professores e sua formação. 3. ed. Lisboa: Dom Quixote, 1997.

RAELIN, J. A. Towards an epistemology of practice. Academy of Management Learning \& Education, v. 6, n. 4, p. 495-519, 2007.

SAYURI, J. Com crise e cortes na ciência, jovens doutores encaram o desemprego: 'Título não paga aluguel'. BBC Brasil. 16 jul. 2018. Disponível em: https://www.bbc.com/portuguese/brasil-44696697. Acesso em: jan 2020.

SCHÖN, D. Educando o profissional reflexivo: um novo design para o ensino e a aprendizagem. Porto Alegre: Artes Médicas, 2000.

WATT, D. On becoming a qualitative researcher: the value of reflexivity. Qualitative Report, v. 12, n. 1, p. 82-101, 2007.

ZEICHNER, K. Para além da divisão entre professor pesquisador e pesquisador acadêmico. In: GERALDI, C. et. al. Cartografias do trabalho docente: professor pesquisador. Campinas: Mercado de Letras; ALB, 1998. p. 207-236.

\section{Como referenciar este artigo}

GOMES, Ana Silvia Alves; ALMEIDA, Ana Cristina Pimentel Carneiro de Almeida. Peculiaridades históricas, panorama atual e desafios na formação de professores doutores. Revista Ibero-Americana de Estudos em Educação, Araraquara, v. 15, n. 2, p. 578-596, abr./jun. 2020. e-ISSN: 1982-5587. DOI: https://doi.org/10.21723/riaee.v15i2.12872

Submetido em: 25/03/2019

Revisões requeridas: 25/08/2019

Aprovado em: 16/10/2019

Publicado em: 20/02/2020 